\title{
PENGAMATAN PERTUMBUHAN COPEPOD SEBAGAI PERSEDIAAN PAKAN ALAMI
}

\section{OBSERVATION OF GROWTH OF COPEPOD AS A NATURAL FOOD SUPPLY}

\author{
Suko Ismi ${ }^{1 *}$, Deny Suhermawan Yusup ${ }^{2}$, \& Sephia Anjani ${ }^{2}$ \\ ${ }^{1}$ Balai Besar Riset Budidaya Laut dan Penyuluhan Perikanan, Gondol-Bali, 81155, Indonesia \\ ${ }^{2}$ Program Studi Biologi FMIPA, Universitas Udayana, Badung-Bali, 8036, Indonesia \\ *E-mail: sukoismi@yahoo.com
}

\begin{abstract}
Copepod is a natural food that has a small size in the naluplii stage and high nutritional value. Suitable as initial feed for marine fish larvae with small mouth openings. The research aims to know the harvest of copepods from Genus Acartia in mass culture to feed larvae in marine fish seed production. The research was conducted in 2020 at the Institute for Mariculture Research and Fisheries Extension, Gondol-Bali. The first study was divided into two steps to determine the growth pattern of copepods as a harvest reference in the second study, which was the culture in 3 jars of $10 \mathrm{~L}$. The second was to determine the number of copepods harvested in mass culture as a feed supply. Culture using three fiber tanks volume 1,000 L, Inoculation was given copepodite stage with a density of $50 \mathrm{ind} / \mathrm{L}$ and given artificial feed and rearing until the density decreases. Based on the pattern of density growth from the first study, the copepod harvest in the second study began on the eighth day. The highest harvest of the nauplii stage was reached on the seventeenth day with $184.7 \mathrm{ind} / \mathrm{L}$ the copepodite stage of 4,4 ind/L. The results of copepod culture are not sufficiently used as the main feed for mass larval production and can only be used as a feed mixture to add nutritional larvae.
\end{abstract}

Keywords: Acartia, copepod, feed, insufficient, larvae, production

\begin{abstract}
ABSTRAK
Copepod adalah pakan alami yang memiliki ukuran kecil pada stadia naupli dengan nilai nutrisi yang tinggi. Cocok sebagai pakan awal larva ikan laut dengan bukaan mulut kecil. Tujuan penelitian mengetahui hasil panen copepod dari Genus Acartia sebagai pakan alami pada kultur masal, untuk pakan larva pada produksi benih ikan laut. Penelitian dilakukan pada Tahun 2020, di Balai Besar Riset Budidaya Laut dan Penyuluhan Perikanan, Gondol-Bali. Penelitian dibagi menjadi 2 tahap, pertama adalah untuk mengetahui pola pertumbuhan copepod sebagai acuan panen pada penelitian ke dua. Copepod dipelihara pada 3 buah toples volume $10 \mathrm{~L}$. Penelitian ke dua untuk mengetahui jumlah copepod yang dipanen pada kultur masal sebagai persedian pakan. Kultur menggunakan 3 bak fiber bervolume $1.000 \mathrm{~L}$. Inokulasi yang diberikan stadia copepodit dengan kepadatan 50 ind/L. Copepod diberi pakan buatan dan dipelihara hingga kepadatan menurun. Berdasarkan pola pertumbuhan kepadatan copepod dari penelitian pertama maka panen copepod penelitian ke dua dimulai hari ke delapan. Hasil panen tertinggi stadia naupli dicapai hari ke tujuh belas dengan kepadatan 184,7 ind/L, stadia copepodit 4,4 ind/L. Hasil kulur copepod tidak cukup dipakai sebagai pakan utama pada produksi larva secara masal dan hanya dapat dipakai sebagai campuran pakan alami untuk menambah nilai nutrisi bagi larva.
\end{abstract}

Kata kunci: Acartia, copepod, larva, pakan, produksi, tidak cukup

\section{PENDAHULUAN}

Beberapa benih ikan laut ekonomis penting seperti bandeng, kakap, kerapu, bawal bintang dan beberapa ikan lainnya sudah dapat diproduksi secara berkesinambungan di hatchery sehingga dapat menyuplai kebutuhan benih pada budidaya laut (Juniyanto et al., 2008; Prijono et al., 2011; Sugama et al., 2012; Rasdi \& Qin, 2018). 
Salah satu faktor penting yang mendukung keberhasilan pemeliharaan larva di hatchery adalah pakan alami yang diberikan. Pada stadia awal larva memerlukan pakan alami (fitoplankton atau zooplankton) yang memiliki nutrisi yang cukup dengan ukuran yang sesuai dengan bukaan mulut larva ikan (Hardianti et al., 2016; Banthani et al., 2019).

Larva ikan pada stadia awal memiliki alat pencernaan yang belum sempurna, hal ini berhubungan dengan kemampuan hidrolisa terhadap pakan yang dikonsumsi (Cahu \& Infante, 2001; Melianawati \& Pratiwi, 2011). Pakan alami merupakan pakan yang tepat untuk larva, mudah dicerna, karena hidup dan bergerak maka menarik untuk dimangsa dan tidak mencemari lingkungan pemeliharaan (Ismi et al., 2000). Copepod adalah salah satu pakan alami dengan nilai nutrisi tinggi yang diperlukan oleh ikan laut (Tocher, 2003; Koszarowska et al., 2019). Salah satu jenis copepod yang banyak di perairan tropis dan baik untuk pakan larva adalah Genus Acartia yang merupakan kelompok crustacea tingkat rendah (Dussart \& Defaye, 2001). Banyak ditemukan di muara dan mangrove karena itu di perairan tersebut banyak ditemukan berbagai jenis larva ikan dan udang (Chew \& Chong, 2011). Copepod stadia naupli $\left(\mathrm{N}_{-1}-\mathrm{N}_{-}\right.$ 6) mempunyai ukuran 100-230 $\mu \mathrm{m}$, pada ukuran tersebut terdapat stadia naupli yang mempunyai lebih kecil untuk pakan awal jika dibandingkan dengan ukuran rotifer 145-150 $\mu \mathrm{m}$. Ukuran naupli tersebut berguna sebagai pakan awal larva ikan laut yang mempunyai bukaan mulut yang kecil, pada stadia selanjutnya bisa dipakai pada larva yang ukurannya lebih besar.

Genus Acartia stadia naupli terdiri dari 6 stadia yaitu stadia $\mathrm{N}_{-1}-\mathrm{N}_{-6}$ dan stadia copepodit 6 stadia $\mathrm{C}_{-1}-\mathrm{C}_{-6}$, dari naupli-1 hingga dapat bertelur copepodite- 6 , memiliki siklus hidup selama10-12 hari dengan jumlah telur antara 11 hingga 30 telur (Golez et al., 2004). Copepod mempunyai siklus hidup yang panjang, hingga saat ini masih terken- dala jumlah produksi (Ajiboye et al., 2010). Pada penelitian ini bertujuan untuk mengamati hasil panen copepod dari Genus Acartia sebagai penyedia pakan alami pada kultur masal, sehingga nantinya dapat dipakai sebagai acuan untuk kultur sebagai persediaan pakan alami untuk membantu produksi benih ikan laut.

\section{METODE PENELITIAN}

Penelitian dilakukan pada bulan Februari-April 2020, di Balai Besar Riset Budidaya Laut dan Penyuluhan Perikanan, Gondol-Bali. Copepod yang dicoba pada penelitian ini adalah dari Genus Acartia. Penelitian dibagi menjadi 2 tahap, pertama adalah pemeliharaan skala kecil dengan menggunakan 3 buah toples volume $12 \mathrm{~L}$ diisi air laut $10 \mathrm{~L}$ yang ditebar Acartia stadia copepodit dengan kepadatan 50 ind/L, Acartia diberi pakan buatan komersial (pakan udang) no: 0 yang berupa tepung sebanyak $0,3 \mathrm{~g} / \mathrm{hari}$. Toples pemeliharaan direndam dalam water bath dengan sistem air mengalir untuk menjaga kestabilan suhu. Penggantian air media kultur dilakukan setiap dua hari sekali secara total (100\%) untuk menghindari kontaminasi, pemeliharaan hingga kepadatan menurun.

Perkembangan Acartia dihitung melalui jumlah kepadatannya dua hari sekali, dengan cara sampling dengan mengambil sampel 1,0 L dari setiap toples yang telah homogen dengan cara diaduk merata. Sampel 1,0 L disaring hingga $10 \mathrm{ml}$, hasil saringan dipindahkan ke microplate (6 lubang). Kemudian jumlah Acartia dalam tiap lubang (K) dihitung dengan bantuan mikroskop. Jumlah individu setiap stadia Acartia pada tiap lubang dihitung dengan rumus berikut untuk mengetahui kepadatan per liter.

Jumlah individu $($ per $\mathrm{L})=$

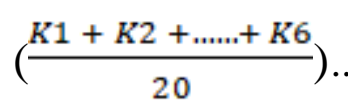


Keterangan: $K$ adalah jumlah individu pada setiap lubang microplate.

Setelah diketahui pola pertumbuhan melalui kepadatan Acartia setiap stadia pada penelitian pertama, dilakukan penelitian ke dua untuk mengetahui jumlah Acartia yang dipanen pada kultur masal untuk persedian pakan. Penelitian ke dua adalah kultur Acartia secara masal menggunakan 3 bak fiber bervolume $1.000 \mathrm{~L}$. Ditebar Acartia stadia copepodit dengan kepadatan 50 ind/L, diberi pakan buatan komersial (pakan udang) no. 0 yang berupa tepung sebanyak 30 gr/hari. Berdasarkan pola pertumbuhan kepadatan Acartia pada penelitian pertama maka pada kultur masal sebagai persediaan pakan panen Acartia dimulai hari ke delapan. Setiap hari Acartia dipanen sebanyak 50\% dan hasilnya dihitung jumlah kepadatan masing-masing stadia pengambilan sampel dengan cara sampling. Setelah panen air media pemeliharaan ditambah dengan air laut yang baru hingga volume $1.000 \mathrm{~L}$, pemeliharaan dilakukan hingga kepadatan menurun.

Parameter yang diamati adalah total kepadatan Acartia dalam kultur 1.000 L, dengan cara penghitungan populasi Acartia setiap hasil pemanenan 50\% dimasukkan ke dalam ember bervolume $10 \mathrm{~L}$, kemudian diambil $10 \mathrm{ml}$ menggunakan beaker glass dan diamati di bawah mikroskop dengan menggunakan microplate 6 lubang. Kemudian jumlah masing-masing stadia Acartia yaitu naupli dan copepodit dalam tiap lubang $(K)$ dihitung dengan menggunakan rumus:

Jumlah individu $($ per $\mathrm{L})=$

$\left(K_{1}+K_{2}+\ldots . .+K_{6} X \frac{1.000 \mathrm{ml}}{10 \mathrm{ml}}\right)$

Keterangan: $K$ adalah jumlah individu pada setiap lubang microplate.

Kualitas air: suhu, oksigen terlarut (DO) dan $\mathrm{pH}$ diukur dengan alat digital, salinitas diukur dengan refraktometer, diukur setiap pagi hari jam 08:00. Data yang diperoleh ditampilkan dalam bentuk gambar dan tabel selanjutnya dianalisis secara deskriptif.

\section{HASIL DAN PEMBAHASAN}

Hasil pengamatan pola pertumbuhan Acartia yang dihitung dari jumlah kepadatan masing-masing stadia pada penelitian pertama yang dikultur volume $10 \mathrm{~L}$ ditampilkan pada (Gambar 1). Nampak bahwa naupli Acartia mencapai puncak kepadatan pertama pada hari ke delapan dengan kepadatan 1812,5 ind/L puncak ke dua dengan kepadatan yang sama dicapai pada hari 20. Copepodit mencapai pucak pertama pada hari ke 12 dengan kepadatan $2725 \mathrm{ind} / \mathrm{L}$, puncak ke dua hari ke 24 dengan kepadatan 2712,5 ind/L. Total kepadatan naupli dan copepodit dicapai pada hari ke 12 dengan kepadatan 3387.7 ind/L dan ke dua hari ke 20 dengan kepadatan 4287,5 ind/L. Mulai hari ke 22 total kepadatan mulai menurun kultur dihentikan pada hari ke 26 . Menurunnya kepadatan dipengaruhi oleh banyak faktor diantaranya, pakan dan lingkungan yang sudah tidak mendukung (Jager et al., 2015; Jager et al., 2017). Pemeliharaan secara terkontrol didalam tangki dengan jenis pakan tertentu berbeda dengan di alam yang terdapat berbagai jenis pakan alami yang cocok untuk copepod yang didukung oleh lingkungan yang luas sehingga tidak terkendala dengan perubahan lingkungan.

Golez et al. (2004) menyatakan bahwa Acartia setelah melewati 5-6 hari stadia naupli $\left(\mathrm{N}_{-1}-\mathrm{N}_{-6}\right)$, akan tumbuh menjadi copepodit $\left(\mathrm{C}_{-1}-\mathrm{C}_{-6}\right)$. Copepodit $6\left(\mathrm{C}_{-6}\right)$ pada kisaran umur hari ke-12 umumnya telah mencapai stadia dewasa ditandai dengan tubuh semakin memanjang, antennule telah mencapai panjang yang sempurna. Acartia betina akan menjadi induk dengan jumlah telur 11 hingga 30 butir. Hasil pengamatan pada pola pertumbuhan copepod (Gambar 1), pada stadia naupli mencapai puncak pertama pada hari ke 8 dengan kepadatan 1812,5 ind/L dan stadia 
copepodite mencapai puncak hari 12 hari dengan kepadatan $2725 \mathrm{ind} / \mathrm{L}$.

Mengacu pada hasil percobaan pertama maka Acartia pada kultur masal $1.000 \mathrm{~L}$ mulai siap dipanen untuk pakan alami adalah hari ke delapan sesuai dengan puncak pertama stadia naupli (Gambar 1). Dari hasil kultur masal (Gambar 2) nampak bahwa panen harian Acartia yang dimulai pada hari ke delapan hasilnya sangat rendah, itu artinya produksi harian Acartia tidak cukup bila dipakai sebagai pakan utama pada pemeliharaan larva secara masal. Jumlah panen tertinggi untuk volume $1.000 \mathrm{~L}$ diperoleh pada hari ke tujuh belas dengan stadia naupli jumlah 184.700 ind atau 184 ind/L, stadia copepodit 4.400 ind atau 4,4 $\mathrm{id} / \mathrm{L}$ dengan jumlah total 189.100 ind atau 189, $1 \mathrm{ind} / \mathrm{L}$.

Bila dilihat dari hasil penelitian ini, produksi Acartia sangat rendah jika dibandingkan dengan rotifer seperti hasil penelitian Rumengan et al. (2012) pada kultur masal rotifer dengan kepadatan awal $150 \mathrm{ind} / \mathrm{ml}$ dalam waktu 24 jam kepadatannya menjadi $207 \mathrm{ind} / \mathrm{ml}$ dan mencapai puncak kepadatan $1.215 \mathrm{ind} / \mathrm{ml}$ pada kultur selama 50 jam. Penghitungan pemberian pakan alami untuk memenuhi kebutuhan pakan pada larva adalah berdasarkan volume air pemeliharaan (Melianawati \& Pratiwi, 2011; Ismi et al., 2018). kepadatan rotifer yang diberikan pada media pemeliharaan sebagai pakan awal adalah 5,0 ind/ml dan akan naik jumlahnya seiring dengan perkembangan larva. Mengacu pada kebutuhan pakan awal tersebut maka jumlah hasil produksi Acartia tidak bisa mencukupi kebutuhan pakan pada produksi masal. Mengingat nilai nutrisi copepod yang tinggi maka copepod hanya bisa dipakai sebagai pakan alami tambahan rotifer (Rasdi \& Qin, 2018).

Copepod mempunyai kandungan nutrisi yang tinggi, terutama kandungan asam lemak esensial eikosapentaenoat 20:5n3 (EPA) dan dokosaheksaenoat 22:6n3 (DHA) yang merupakan asam lemak tidak jenuh rantai panjang (HUFA) yang dibutuhkan bagi ikan laut (Higgs \& Dong, 2000; Seiffert et al., 2001; Tocher, 2003). Menurut (Watanabe, 1978) dalam (Ismi \& Asih, 2014), bahwa Acartia sp. mengandung 20:5n3 sebesar 20,1\% dan 22:6n3 sebesar

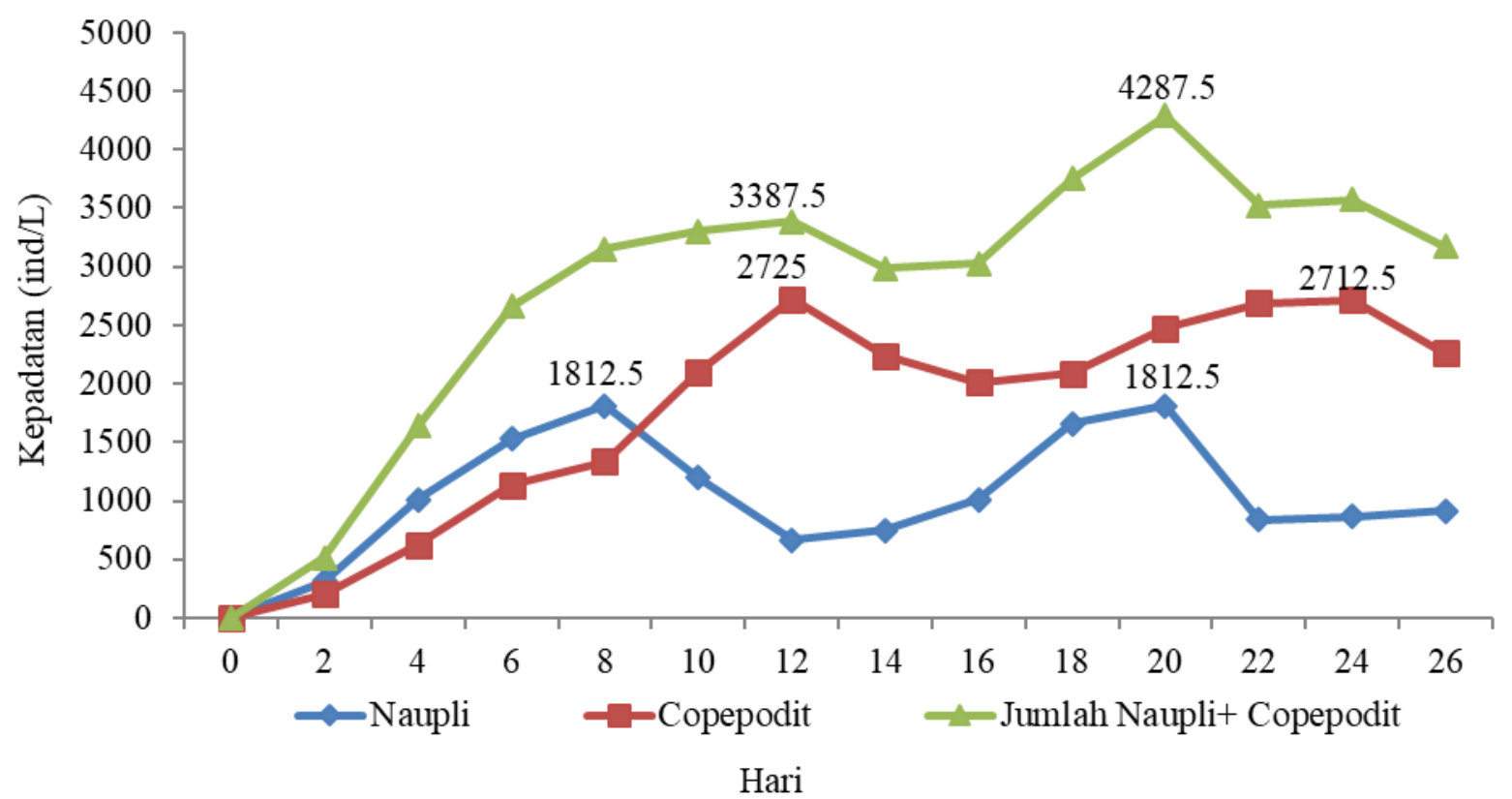

Gambar 1. Kepadatan masing-masing stadia copepod yang dikultur pada volume 101 secara terkotrol. 


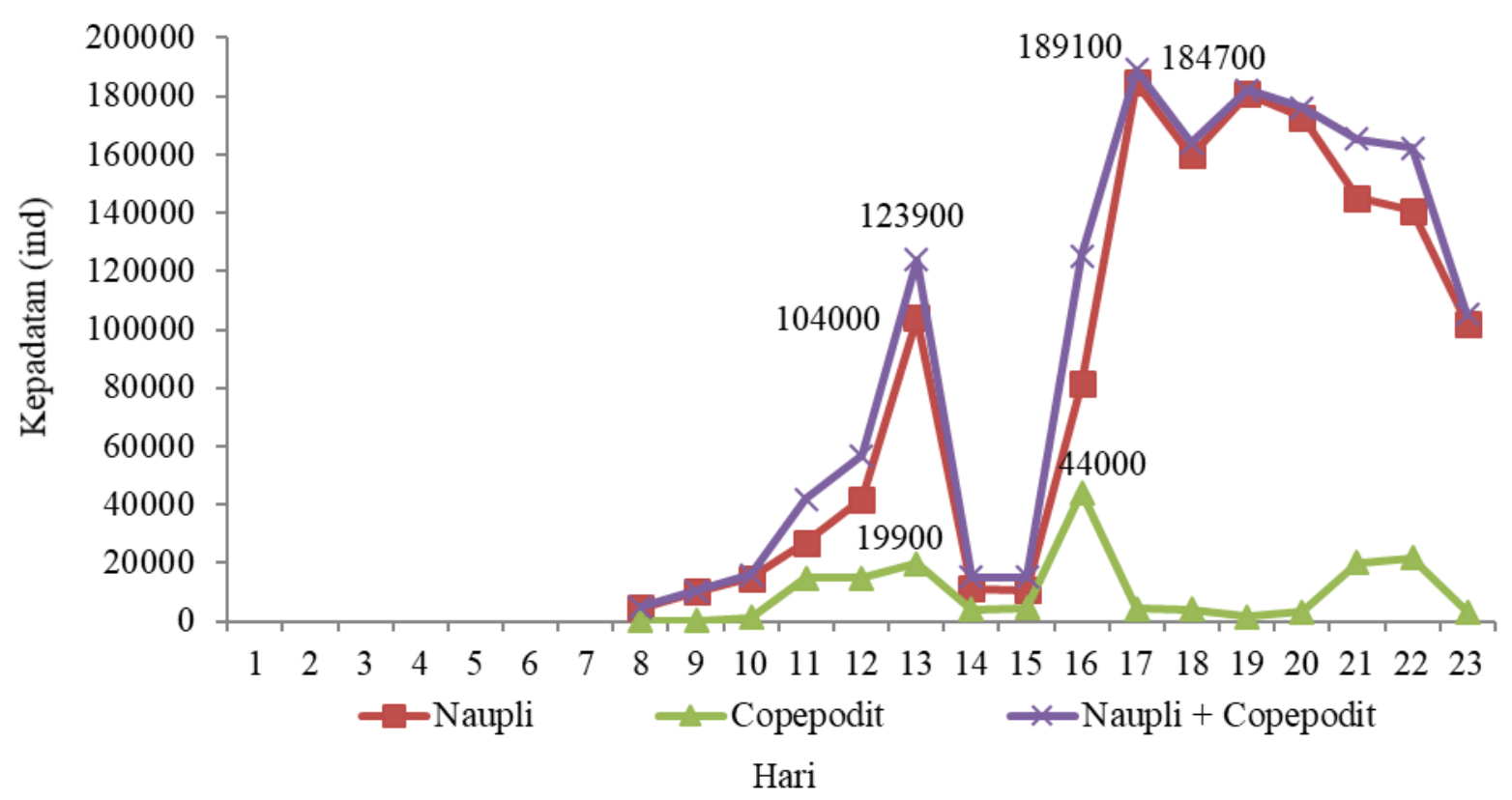

Gambar 2. Kepadatan hasil panen masing-masing stadia copepod yang dikultur pada volume 1.0001.

$28,6 \%$ sedangkan rotifer yang diberi pakan Chlorella sp. mempunyai kandungan 20:5n3 sebesar 24,1\% dan 22:6n3 sebesar 0,9\%. Jumlah produksi Acartia sp. untuk pakan utama tidak bisa mencukupi maka pemberian pakan alami campuran rotifer dengan copepod mempunyai nutrisi lebih baik dibandingkan jika hanya rotifer saja (Ismi et al., 2000; Ajiboye, 2010).

Ukuran naupli tersebut berguna sebagai pakan awal larva ikan laut yang mempunyai bukaan mulut yang kecil, pada stadia selanjutnya bisa dipakai pada larva yang ukurannya lebih besar. Menurut Ismi et al. (2000) copepod dari Acartia sp. cocok utuk pakan awal larva kerapu bebek (Cromileptes altevelis) dengan lebar bukaan mulut atas pada hari ke-3: $\pm 143 \mu \mathrm{m}$, hari ke4: $\pm 152 \mu \mathrm{m}$, hari ke-5: $\pm 170 \mu \mathrm{m}$, hari ke-6: $\pm 190 \mu \mathrm{m}$, hari ke-7: $\pm 210 \mu \mathrm{m}$ dan hari ke-8: $\pm 232 \mu \mathrm{m}$, sedangkan rotifer tipe SS yang diberikan mempunyai ukuran 145-150 $\mu \mathrm{m}$. Ukuran stadia $\mathrm{N}_{-1}: 100 \mu \mathrm{m}, \mathrm{N}_{-2}: 120 \mu \mathrm{m}, \mathrm{N}_{-3}$ : $150 \mu \mathrm{m}, \mathrm{N}_{-4}: 170 \mu \mathrm{m}, \mathrm{N}_{-5} .200 \mu \mathrm{m}$ dan $\mathrm{N}_{-6}$ : $230 \mu \mathrm{m}$.

Demikian juga yang terjadi pada larva kerapu sunu (Leopardus plectropomus) yang mempunyai bukaan mulut awal lebih kecil dari kerapu bebek yaitu sekitar 0,126 $\pm 0,013$ $\mu \mathrm{m}$ akan susah untuk menangkap pakan jika hanya diberi rotifer (Aslianti et al., 2008). Hasil pengamatan Sudewi et al. (2020) menyatakan bahwa larva ikan kerapu sunu mampu memakan rotifer pada saat umur 5 dengan kisaran 3,0-10 ind, agar larva dapat memangsa pakan setelah buka mulut maka pada saat awal pemeliharaan perlu nauplius Acartia yang berukuran kecil $\left(\mathrm{N}_{-1}-\mathrm{N}_{-2}\right)$ dengan jumlah yang cukup.

Kualitas air selama pemeliharaan disajikan pada (Tabel 1), hasil pengamatan kualitas air masih berada pada kisaran yang layak untuk kehidupan Acartia. Oksigen terlarut (DO) lebih dari 3,0 mg/L adalah layak untuk kehidupan plankton termasuk Acartia, sedangkan $\mathrm{pH}$ mampu hidup dengan rentang $\mathrm{pH}$ 5,5-9,2 dengan $\mathrm{pH}$ optimal pada rentang $\mathrm{pH} 7,0-8,5$. Menurut Milione \& Zeng (2008), Acartia sp. dapat hidup dan tumbuh normal pada suhu $23-35{ }^{\circ} \mathrm{C}$, optimal pada suhu $26-30{ }^{\circ} \mathrm{C}$, sedangkan menurut Nugraha \& Hismayasari (2011), bisa hidup pada salinitas berkisar antara 15-70 g/L dan suhu antara $17-30{ }^{\circ} \mathrm{C}$. Copepod Oithona davisae 
Tabel 1. Kualitas air media kultur copepod selama penelitian.

\begin{tabular}{lcc}
\hline \multicolumn{1}{c}{ Parameter } & \multicolumn{2}{c}{ Volume media kultur (L) } \\
\cline { 2 - 3 } & 10 & 1000 \\
\hline Suhu $\left({ }^{\circ} \mathrm{C}\right)$ & $27,0-34,0$ & $26,0-35,0$ \\
Oksigen terlarut (DO) $(\mathrm{mg} / \mathrm{L})$ & $4,3-5,1$ & $3,7-4,8$ \\
$\mathrm{pH}$ & $7,2-8,1$ & $7,4-8,0$ \\
Salinitas (g/L) & $29,0-350$ & $30,0-35,0$ \\
\hline
\end{tabular}

banyak ditemukan pada perairan dengan salinitas $17-18 \mathrm{~g} / \mathrm{L}$ dengan suhu $16-17{ }^{\circ} \mathrm{C}$ (Temnykh \& Shuhei, 2012). Suhu optimum untuk Apocyclops borneoensis adalah 33 ${ }^{\circ} \mathrm{C}$ dengan salinias 20 ppt (Imanto \& Sumiarsa, 2010).

\section{KESIMPULAN}

Copepod sebagai zooplankton yang merupakan pakan alami dengan nutrisi yang baik untuk larva tetapi mempunyai siklus hidup yang lama yaitu sekitar 12 hari, dengan kepadatan pada produksi kultur masal rendah sehingga tidak dapat mencukupi untuk pakan utama larva. Dari hasil penelitian ini maka copepod dari genus Acartia hanya bisa dipakai sebagai campuran pakan larva bersamaan dengan rotifer, sehingga nutrisi pakan yang diberikan untuk larva lebih baik.

\section{UCAPAN TERIMAKASIH}

Terima kasih kepada pihak Balai Besar Riset Budidaya Laut dan Penyuluhan Perikanan, Gondol yang telah menyediakan sarana untuk penelitian ini. Kami juga mengucapkan terima kasih kepada Bapak Kurdi dan Bapak Komang Suwitra selaku teknisi pakan alami atas bantuan dan peran sertanya hingga penelitian ini selesai.

\section{DAFTAR PUSTAKA}

Ajiboye, O., A.F. Yakubu, T.E. Adam, E.D. Olaji, \& N.A. Nwogu. 2010. A review of the use of copepods in marine fish larviculture. Reviews in Fish Biology and Fisheries, 21(2):
225-246.

https://doi.org/10.1007/s11160-0109169-3

Aslianti, T., K. Suwirya, \& Asmanik. 2008. Teknologi pemeliharaan larva kerapu sunu (Plectropomus leopardus) secara masal. J. Ris. Akuakultur, 3(1): $1-11$.

https://doi.org/10.15578/jra.3.1.2008. 1-11

Banthani, G., Iskandar, R. Rostika, T. Herawati, \& I.B.B. Suryadi. 2019. Efektifitas pemberian rotifera (Brachionus rotundiformis) yang diperkaya dengan taurin dan glutamin terhadap kelangsungan hidup dan pertumbuhan larva ikan kerapu sunu (Plectropomus leopardus). J. Perikanan dan Kelautan, 10(2): 2227.

https://core.ac.uk/download/pdf/2948 63073.pdf.

Cahu, C. \& J.Z. Infante. 2001. Substitution of live food by formulated diets in marine fish larvae. Aquaculture, 22: 161-180. https://doi.org/10.1016/S00448486(01)00699-8

Chew, L.L. \& Chong V.C. 2011. Copepod community structure and abundance in a tropical mangrove estuary, with comparisons to coastal waters. Hydrobiologia, 666(1): 127-143. https://doi.org/10.1007/s10750-0100092-3

Dussart, B.H. \& D. Defaye. 2001. Introduction to the copepoda. Backhuys. Leiden, 344 p. 
Golez, M.A., N. Salvacion, T. Takashi, T. Ishimaru \& A. Ohno. 2004. Postembryonic development and reproduction of Pseudodiaptomus annandalei (Copepoda: Calanoida)Plankton Biology and Ecology, 51(1): 15-25. http://www.plankton.jp/PBE/issue/vol 51_1/vol51_1_015.pdf

Hardianti, Q., Rusliadi, \& Mulyadi. 2016. Effect of feeding made with different composition on growth and survival seeds of barramundi (Lates calcarifer, Bloch). J. Penelitian Perikanan Indonesia, $\quad 9(1)$ : $1-10$. https://doi.org/10.46989/001c.20539

Higgs, D.A. \& F.M. Dong. 2000. Lipids and fatty acids. In: Encyclopedia of Aquaculture (ed. R.R. Stickney), John Wiley and Sons, Inc., New York, 476-496 pp.

Imanto, P.T. \& G.S. Sumiarsa. 2010. Keragaan copepoda cyclopoida: Apocyclops sp. Pada kondisi kultur. J. Ris. Akuakultur, 5 (3): 363-372.

https://doi.org/10.15578/jra.5.3.2010. 363-372

Ismi, S., Wardoyo, K. M. Setiawati, J. H. Hutapea \& T. Aslianti. 2000. Penggunaan copepod Acartia sp. Sebagai makanan pada pemeliharaan larva kerapu bebek (Cromilepfes altivelis). J. Penelitian Perikanan Indonesia, 6 (1): 19-23.

https://doi.org/10.15578/jppi.6.1.2000 .19-23

Ismi, S. \& Y.N. Asih. 2014. Peningkatan jumlah dan kualitas produksi benih ikan kerapu melalui pengkayaan pakan alami. J. Ilmu dan Teknologi Kelautan Tropis, 6(2): 403414. https://doi.org/10.29244/jitkt.v6i 2

Ismi, S., J.H. Hutapea, D. Kusumawati, \& Y.N. Asih. 2018. Perkembangan morfologi dan perilaku larva ikan kerapu hibrida cantik pada produksi massal. J. Ilmu dan Teknologi Kelautan Tropis, 10(2): 431-440. https://doi.org/10.29244/jitkt.v10i2.21 825

Jager, T, I. Salaberria, \& B.H. Hansen. 2015. Capturing the life history of the marine copepod Calanus sinicus into a generic bioenergetics framework. Ecol Model, 299: 114120.

https://doi.org/10.1016/j.ecolmodel.2 014.12.011

Jager, T, I. Salaberria, D. Altin, T. Nordtug, \& B.H. Hansen. 2017. Modeling the dynamics of growth, development and lipid storage in the marine copepod Calanus finmarchicus. Mar Biol., 164(1): 1-31. https://doi.org/10.1007/s00227-0163030-8

Juniyanto, N.M., S. Akbar \& Zakimin, 2008. Breeding and seed production of silver pompano (Trachinotus blochii, Lacepede) at the mariculture Development Center of Batam. Marine Fish Aquaculture Network. 46-49 pp. http://library.enaca.org/AquacultureA sia/Articles/april-june-2008/14juniyanto-april-08.pdf.

Koszarowska, M.M, L.D. Głowacka, \& G. Weydmann. 2019. Influence of environmental factors on the population dynamics of key zooplankton species in the Gulf of Gdańsk (southern Baltic Sea). Oceanologia, 61(1): 17-25. https://doi.org/10.1016/j.oceano.2018. 06.001

Melianawati, R. \& R. Pratiwi. 2011. Pola aktivitas pencernaan larva ikan kerapu macan (Epinephelus fuscoguttatus Forsskal, 1775). J. Ris. Akuakultur, 6(1): 51-63. https://doi.org/10.15578/jra.6.1.2011. 51-61

Milione, M. \& Zeng, C. 2008. The effects of temperature and salinity on 
population growth and egg hatching success of the tropical calanoid copepod, Acartia sinjiensis. Aquaculture, 275: 116-123. https://doi.org/10.1016/j.aquaculture. 2007.12.010

Nugraha, M.F.I. \& I.B. Hismayasari. 2011. Copepoda: sumbu kelangsungan biota akuatik dan kontribusinya untuk akuakultur. Media Akuakultur, 6 (1): 13-20.

https://doi.org/10.15578/ma.6.1.2011. $13-20$

Prijono, A., T. Aslianti, T.S. Dharma, \& N.A. Giri. 2011. Petunjuk teknis perbenihan ikan bandeng (Chanos chanos Forskal). Balai Besar Penelitian dan Pengembangan Budidaya Laut. Badan Penelitian dan Pengembangan Kelautan dan Perikanan. Kementerian Kelautan dan Perikanan. $44 \mathrm{hlm}$.

Rasdi, N.W. \& J.G. Qin. 2018. Copepod supplementation as a live food improved growth and survival of Asian seabass Lates calcarifer larvae. Aquaculture Research. 49(11): 36063613. https://doi.org/10.1111/are.13828

Rumengan, I.F.M., Budiyanto, R. Medosa, D. Dewanto, \& D Limbong. 2012. Mekanisme sistem panen pada kultur massal rotifer Brachionus rotundiformis. J. Ris. Akuakultur, 7(1): 111-119.

https://doi.org/10.15578/jra.7.1.2012. 111-119

Seiffert, M.E.B., V.R. Cerqueira, \& L.A.S. Madureira. 2001. Effect of dietary $(n-3)$ highly unsaturated fatty acids on growth and survival of fat snook (Centropomus parallelus, Pisces: Centropomidae) larvae during first feeding. Brazilian J. of Medical and Biological Research, 34: 645-651. https://doi.org/10.1590/s0100879x2001000500013.

Sudewi, Y.M. Asih, \& A. Nasukha. 2020. Studi bukaan mulut larva kerapu sunu (Plectropomus leopardus) dan kesesuaian ukuran pakan alami. $J$. of Fisheries and Marine Research, 4(1): 87-93.

https://doi.org/10.21776/ub.jfmr.2020 .004 .0113

Sugama, K., M.A. Rimmer, S. Ismi, I. Koesharyani, K. Suwirya, N.A. Giri, \& V.R. Alava. 2012. Hatchery management of tiger grouper (Epinephelus fuscoguttatus): a bestpractice manual. Australian Centre for International Agricultural Research (ACIAR) 2012. 66 p. https://enaca.org/enclosure.php?id=475

Temnykh, A. \& N. Shuhei. 2012. New record of the planktonic copepod Oithona davisae in The Black Sea with Notes on The Identity of "Oithona brevicornis". Reabic: Aquatic Invasions, 7(3): 425-431. https://doi.org/10.3391/ai.2012.7.3.01 3

Tocher, D.R., 2003. Metabolism \& functions of lipids and fatty acids in teleost fish. Rev. Fish Sci., 11: 107-184. https://doi.org/10.1080/713610925

Submitted : 26 April 2021

Reviewed: 28 May 2021

Accepted : 11 July 2021

\section{FIGURE AND TABEL TITLES}

Figure 1. The growth pattern of copepods was cultured at a volume of $10 \mathrm{~L}$. Figure 2. The growth pattern of copepods was cultured at a volume of 1,000 L. Table 1. Water quality of copepod culture media during the experimet. 